This document is confidential and is proprietary to the American Chemical Society and its authors. Do not copy or disclose without written permission. If you have received this item in error, notify the sender and delete all copies.

\title{
Internal Hydration Properties of Single Bacterial Endospores Probed by Electrostatic Force Microscopy
}

\begin{tabular}{|r|l|}
\hline Journal: & ACS Nano \\
\hline Manuscript ID & nn-2016-06578u.R2 \\
\hline Manuscript Type: & Article \\
\hline Date Submitted by the Author: & $\mathrm{n} / \mathrm{a}$ \\
\hline Complete List of Authors: & $\begin{array}{l}\text { Van Der Hofstadt, Marc; Universitat de Barcelona; Institut de Bioenginyeria } \\
\text { de Catalunya } \\
\text { Fabregas, Rene; Institut de Bioenginyeria de Catalunya; Universitat de } \\
\text { Barcelona } \\
\text { Millan-Solsona, Ruben; Institut de Bioenginyeria de Catalunya } \\
\text { Juarez, Antonio; Institute for Bioengineering of Catalonia, Cellular } \\
\text { Biotechnology; Institut de Bioenginyeria de Catalunya } \\
\text { Fumagalli, Laura; University of Manchester, School of Physics and } \\
\text { Astronomy - condensed matter group } \\
\text { Gomila, Gabriel; Universitat de Barcelona; Institut de Bioenginyeria de } \\
\text { Catalunya }\end{array}$ \\
\hline
\end{tabular}




\title{
Internal Hydration Properties of Single Bacterial
}

\section{Endospores Probed by Electrostatic Force}

\section{Microscopy}

\author{
Marc Van Der Hofstadt ${ }^{1,2}$, Rene Fabregas ${ }^{1,2}$, Ruben Millan-Solsona ${ }^{1}$, Antonio Juarez ${ }^{1,3}$, Laura \\ Fumagalli $^{4}$ and Gabriel Gomila*,1,2 \\ ${ }^{1}$ Institut de Bioenginyeria de Catalunya (IBEC), c/ Baldiri i Reixac 11-15, 08028, Barcelona, \\ Spain \\ ${ }^{2}$ Departament d'Enginyeries: Electrònica, Universitat de Barcelona, C/ Martí i Franqués 1, \\ 08028, Barcelona, Spain \\ ${ }^{3}$ Departament de Microbiologia, Universitat de Barcelona, Av. Diagonal 643, 08028 Barcelona, \\ Spain \\ ${ }^{4}$ School of Physics and Astronomy, University of Manchester, Oxford Road, Manchester, M13 \\ 9PL, United Kingdom \\ *ggomila@ibecbarcelona.eu
}




\begin{abstract}
We show that the internal hydration properties of single Bacillus cereus endospores in air under different relative humidity $(\mathrm{RH})$ conditions can be determined through the measurement of its electric permittivity by means of quantitative electrostatic force microscopy (EFM). We show that an increase in the $\mathrm{RH}$ from $0 \%$ to $80 \%$ induces a large increase in the equivalent homogeneous relative electric permittivity of the bacterial endospores, from $\sim 4$ up to $\sim 17$, accompanied only by a small increase in the endospore height, of just a few nanometers. These results correlate the increase of the moisture content of the endospore with the corresponding increase of environmental RH. 3D finite element numerical calculations, which include the internal structure of the endospores, indicate that the moisture is mainly accumulated in the external layers of the endospore, hence preserving the core of the endospore at low hydration levels. This mechanism is different from what we observe for vegetative bacterial cells of the same species, in which the cell wall at high humid atmospheric conditions is not able to preserve the cytoplasmic region at low hydration levels. These results show the potential of quantitative EFM under environmental humidity control to study the hygroscopic properties of small scale biological (and non-biological) entities and to determine its internal hydration state. A better understanding of nano-hygroscopic properties can be of relevance in the study of essential biological processes and in the design of bio-nanotechnological applications.
\end{abstract}

\title{
KEYWORDS
}

Electrostatic Force Microscopy, bacterial endospores, relative humidity, electric permittivity, nano-hygroscopicity. 
The depletion of nutrients or the presence of harsh environmental conditions activates effective survival strategies on living organisms. One of the best known examples is the production of endospores by prokaryotes, such as the genus Bacillus or Clostridium. ${ }^{1}$ Endospores consist of micrometric capsules produced by bacterial cells where replicated DNA is compacted into a core region and surrounded by protein and lipid membrane layers, of which the more relevant are (from inside to outside) the inner membrane, the cortex and the coat. Endospores can remain in a metabolically dormant state in dry conditions for decades and are capable of germinating back into a vegetative bacterial cell within minutes when appropriate environmental conditions are established (e.g. presence of water, nutrients, appropriate temperature, etc.). In addition to resist desiccation conditions, endospores are capable to resist other severe conditions, such as high temperatures (even combined with high hydrostatic pressures), radiations or toxic chemicals, ${ }^{2-4}$ making them a great threat in clinical medicine, food industry or terrorism.

The outstanding resistance of dormant endospores is believed to be strongly related to its capability to preserve the core at low hydration levels under atmospheric conditions. ${ }^{5-8}$ At low hydration levels important core enzymes remain inactive $e^{3,7,9}$ and do not denature irreversibly upon a temperature increase. ${ }^{9,10}$ In addition, the core is believed to be in high viscous state (glass or gel, still under discussion), which further reduces the diffusive molecular motions and further contributes to preserve the molecular structure of the proteins and the genome. ${ }^{11-13}$ This peculiar internal hydration distribution seems to be, also, at the basis of the large forces and stresses generated by volume changes in endospores upon exposure to environmental relativity humidity modifications. ${ }^{14-16}$ This latter property has been used very recently to develop surprising technological applications, including energy-harvesting devices able to generate electrical power 
from an evaporating body of water ${ }^{16,17}$ and electromechanical tunneling graphene quantum dotspore devices. $^{18}$

Therefore, understanding the internal hydration properties of endospores under a large range of varying environmental humidity conditions (hygroscopicity) is a subject of major interest both to understand the fundamental mechanisms of endospore resistance, as well as, to design specific technological applications.

In recent years a significant effort has been made to develop micro/nanotechniques able to examine the internal hydration properties of endospores at the single endospore level. These techniques allow providing direct answers to this problem not subject to the averaging associated to traditional population endospore studies. ${ }^{19-23}$ The single endospore techniques used for hygroscopic studies include high resolution secondary ion spectroscopy (NanoSIMMS), ${ }^{24}$ confocal Raman Microspectroscopy, ${ }^{25}$ fluorescence redistribution after photobleaching microscopy (FRAP), ${ }^{5,26}$ automated scanning optical microscopy ${ }^{14}$ and microsystem techniques, such as single particle levitation ${ }^{27}$ and suspended microchannel resonators. ${ }^{28}$ In spite of the valuable results obtained by the above mentioned techniques, they still suffer from some inherent limitations, including the lack of spatial resolution (nanoscale), of being able to work in situ on a broad range of RH levels on a given endospore in a non-destructive way or of having sensitivity to the internal hydration properties. We note that other nanotechniques, such as Atomic Force Microscopy (AFM) or tip-enhanced Raman scattering (TERS), have been applied to endospore research, but not to the specific problem of determining the endospore hydration properties. ${ }^{29-32}$

Here, we overcome some of the limitations of the above mentioned techniques by addressing the problem of measuring the internal hydration properties of single bacterial endospores under variable environmental relative humidity conditions by using quantitative Electrostatic Force 
Microscopy (EFM). EFM is a scanning probe microscopy technique sensitive to the local dielectric properties of the samples. ${ }^{33,34}$ Examples showing this ability include numerous applications to samples of non-biological origin (thin and thick oxides, ${ }^{35}$ polymer films, ${ }^{36-38}$ nanowires, ${ }^{39}$ nanotubes ${ }^{40,41}$ or nanoparticles ${ }^{42-45}$ ), and of biological origin (single bacterial cells, ${ }^{46,47}$ single virus particles, ${ }^{45}$ solid supported biomembranes, ${ }^{48}$ protein complexes ${ }^{49}$ or DNA molecules). ${ }^{50}$ EFM has two important properties relevant for the present application, namely, (i) it is sensitive to the internal dielectric properties of the samples, since it is based in the measurement of long range electric forces ${ }^{51-53}$ and, (ii) it is also sensitive to the presence of moisture in the sample, ${ }^{46}$ due to the large electric permittivity of water $\left(\varepsilon_{r, \text { water }} \sim 80\right)$. The above mentioned features of show that this technique is optimal to probe in situ and in a nondestructive way the internal hydration properties of small scale biological samples, and bacterial endospores in particular, under varying environmental humidity conditions.

In order to achieve this goal we used an environmental EFM system able to cover a broad range of $\mathrm{RH}$ levels (from $0 \%$ to $80 \%$ ). In addition, we developed a data analysis methodology to quantitatively compare the results under such different environmental humidity conditions. Finally, we implemented accurate 3D simulation methods to quantify the EFM measurements and to determine the internal electric permittivity properties of the endospore, and from there, to assess the internal hydration properties of a single bacterial endospore.

\section{RESULTS AND DISCUSSION}

Figure 1 shows AFM topographic and EFM capacitance gradient images of an individual endospore from $B$. cereus under three different environmental humidity conditions corresponding to relative humidity RH $0 \%$ (first column), $40 \%$ (second column) and $80 \%$ (third 
column) (see Materials and Methods and Supporting Information for experimental details). The topographic AFM images (Figures $1 \mathrm{a}, 1 \mathrm{~b}$ and 1c) reveal a bacil-like shape for the mature endospore with lateral dimensions (length, width) $\sim 2020 \mathrm{~nm}$ and $\sim 980 \mathrm{~nm}$, respectively, obtained after tip deconvolution analysis (see Supporting Information). Concerning the height, we observe a systematic and small increase with $\mathrm{RH}$ levels, giving values of $\sim 825 \mathrm{~nm}, \sim 842 \mathrm{~nm}$ and $\sim 858$ nm corresponding to RH values of $\sim 0 \%, 40 \%$ and $80 \%$, respectively (see topographic crosssection profiles in Figure 1d). Similar size variations have been also reported by other authors by using different methods. ${ }^{14}$

Figures 1e, 1f and $1 \mathrm{~g}$ show lift mode capacitance gradient EFM images of the bacterial endospore obtained with the same tip at an approximately similar lift distances, $z_{l i f t}=53 \mathrm{~nm}, 56$ $\mathrm{nm}$ and $57 \mathrm{~nm}$, respectively. The images show a decrease of the capacitance gradient as the tip moves from the substrate to the top of the endospore, being the decrease smaller the higher the relative humidity (see cross-section profiles in Figure 1h). This behavior is systematically reproduced at different lift distances, as shown in Figure 1n where we plot the absolute values of the lift capacitance gradient on the center of the endospore (circles) and on the substrate (squares), as a function of lift distance (see also Supporting Information). We note that the change of environmental RH produces basically a variation of the capacitance gradient on the endospore, and not on the substrate. To rule out that this variation on top of the endospore at the different environmental $\mathrm{RH}$ is due to a topographic cross-talk effect associated to the small increase in the endospore height, we determined the intrinsic capacitance gradient images, ${ }^{47}$ in which topographic crosstalk contributions are removed. To obtain these images we used the topographic images and an approach curve measured on a bare part of the substrate (Figure $1 \mathrm{~m}$, black line), as explained elsewhere. ${ }^{47}$ The resulting intrinsic capacitance gradient images are 
(a)

$\mathrm{RH} 0 \%\left(\mathrm{z}_{\text {iff }}=53 \mathrm{~nm}\right)$

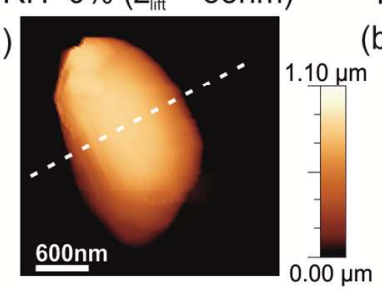

(e)

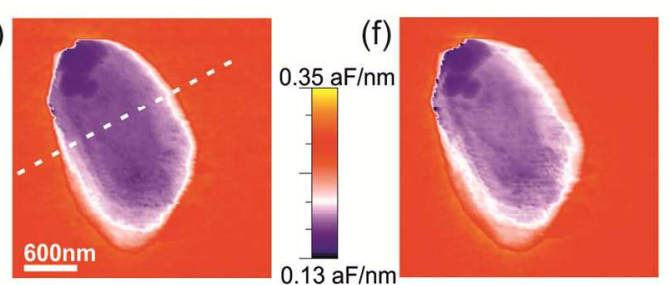

(i)

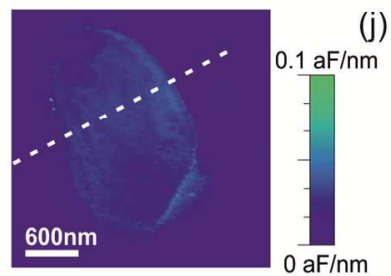

(m)

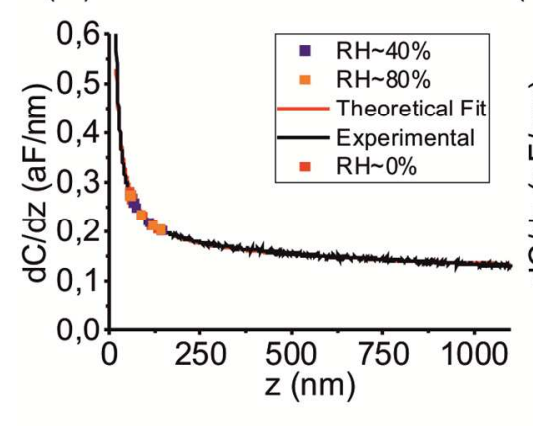

(n)

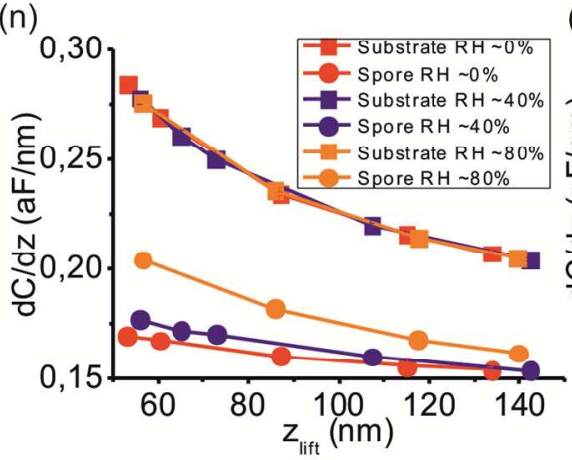

(c)

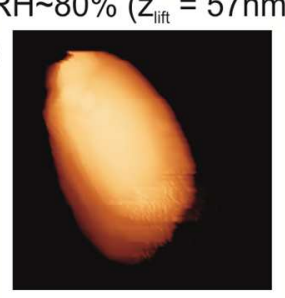

(g)

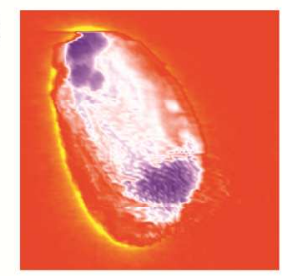

(k)

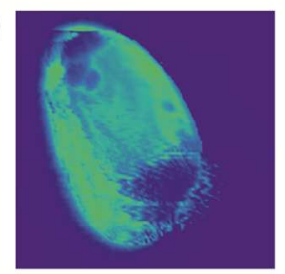

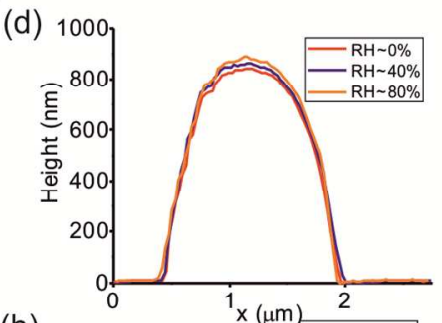

(h)

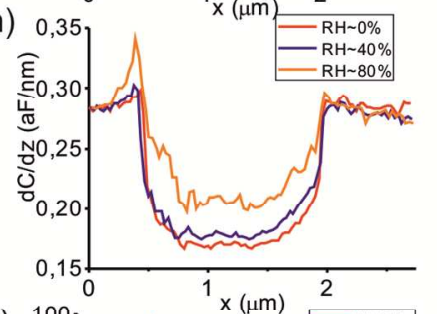

(I) $100 \quad \times$ (IIm) ${ }^{2}{ }_{\mathrm{RH}-0 \%}$

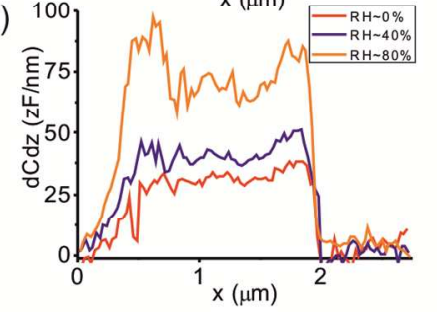

(o)

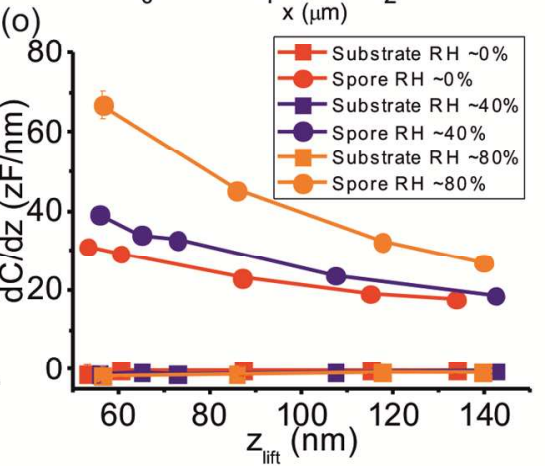

Figure 1. (a) Topographic, (e) lift capacitance gradient and (f) intrinsic capacitance gradient images of a $B$. cereus endospore obtained under dry conditions $(\mathrm{RH} \sim 0 \%)$ at a lift distance $z_{\text {lift }}=53$ nm. (b), (f) and (j) idem at $\mathrm{RH} 40 \%$ and lift distance $z_{\text {lifi }}=56 \mathrm{~nm}$. (c), (g) and (k) idem at $\mathrm{RH} \sim 80 \%$ and lift distance $z_{\text {lift }}=57 \mathrm{~nm}$. (d), (h) and (l) show the corresponding cross-section profiles along the lines drawn on the images. (m) Capacitance gradient approach curve on the 
bare substrate (black line). Symbols represent the values extracted from the EFM lift images on the substrate and used to determine the lift distances (red $\mathrm{RH} \sim 0 \%$, blue $\mathrm{RH} \sim 40 \%$ and orange $\mathrm{RH} \sim 80 \%$ ). The red line (almost indistinguishable) is a theoretical fit to the experimental data used to calibrate the tip geometry, giving in this case $R=133 \pm 2 \mathrm{~nm}, \theta=20 \pm 1^{\circ}$ and $k_{\text {stray }}=0.066 \pm 0.002 \mathrm{aF} / \mathrm{nm}$. (n) Lift capacitance gradient values as a function of the lift distances obtained from the lift EFM images on the bare substrate (squares) and on the center of the endospore (circles). (o) Idem for the intrinsic capacitance gradient images. The error in the data represented by the symbols is of the order of $0.002 \mathrm{aF} / \mathrm{nm}$, being smaller than the symbol size.

\begin{abstract}
Altogether, these results imply that the variation in the lift EFM capacitance gradient images observed at increasing environmental humidity conditions is directly related to a variation in the electric permittivity properties of the endospore, and not to a change in the endospore dimensions. The variation in the electric permittivity, in turn, can be unambiguously correlated to an increase of the moisture content of the endospore, thus confirming the ability of EFM to assess the hygroscopic properties of small scale biological samples. Note that EFM measurements are more sensitive to the hygroscopic properties than the AFM images themselves, as it can be seen by comparing the relative variations produced by a RH change on the electric signals (Figure 11) and on the topographic profiles (Figure 1d). The reason being that the electric permittivity of water $\left(\varepsilon_{r, w a t e r} \sim 80\right)$ is much larger than that of the dry biochemical components of the endospore $\left(\varepsilon_{r, \text { proteins }} \sim 3-5\right.$ for proteins, ${ }^{48,49} \varepsilon_{r, \text { lipids }} \sim 2$ for lipids ${ }^{48}$ and $\varepsilon_{r, D N A} \sim 8$ for DNA). ${ }^{45,49}$ This fact makes its presence easily detectable in the EFM images even when small amounts of moisture are present.
\end{abstract}


As a control, a similar analysis has been performed using a $B$. cereus vegetative cell instead of the endospore. Results are shown in Figure 2. The lateral dimensions of the vegetative cell obtained from the topographic images (Figures $2 \mathrm{a}, 2 \mathrm{~b}$ and $2 \mathrm{c}$ ) are $l \sim 3450 \mathrm{~nm}$ and $w \sim 960 \mathrm{~nm}$, while the heights are $h \sim 622 \mathrm{~nm}, 643 \mathrm{~nm}$ and $670 \mathrm{~nm}$ for $\mathrm{RH} \sim 0 \%, 40 \%$ and $80 \%$, respectively (see also topographic cross-section profiles in Figure 2d). The dielectric response of the vegetative bacterial cell to environmental $\mathrm{RH}$ changes is qualitatively very similar to the one found for the endospore. This fact is shown in the capacitance gradient lift EFM images in Figures $2 \mathrm{e}, 2 \mathrm{f}$ and $2 \mathrm{~g}$ obtained at approximately the same lift distance, $z_{\text {lifi }}=89 \mathrm{~nm}, 85 \mathrm{~nm}$ and 90 $\mathrm{nm}$, respectively (see also the capacitance gradient cross-section profiles in Figure $2 \mathrm{~h}$ and the values on the center of the endospore for different lift distances in Figure $2 \mathrm{n}$ and in the Supporting Information). 
(a)

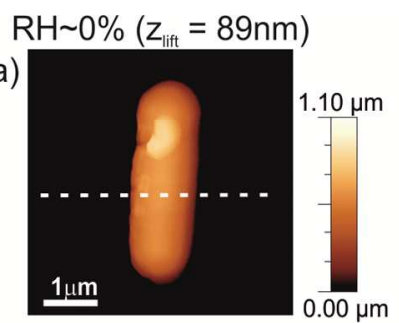

(e)

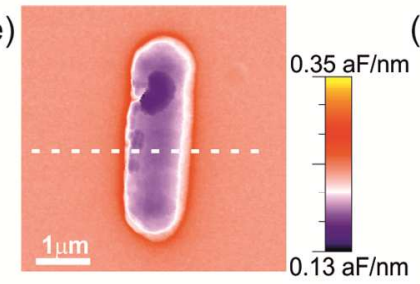

(i)
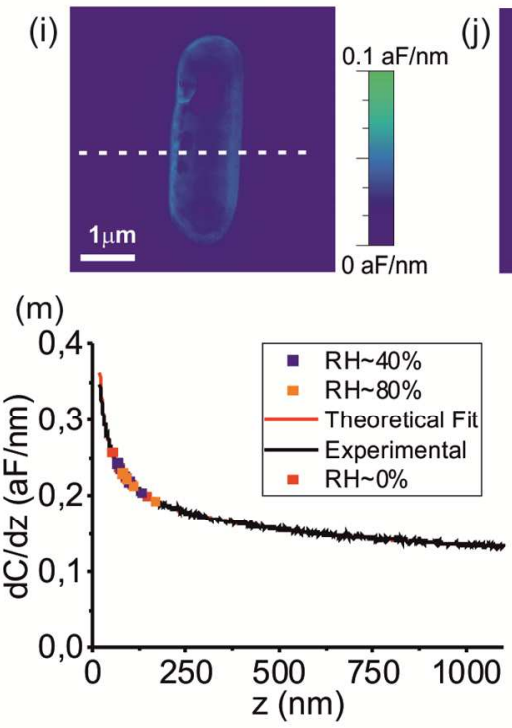

(f)
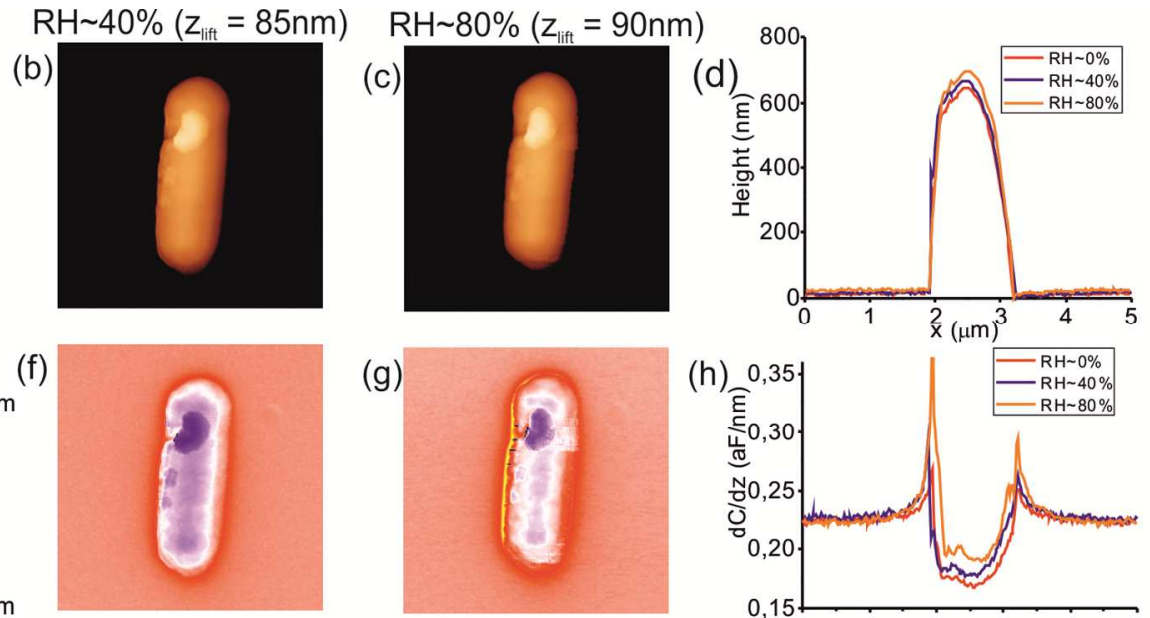

(g)
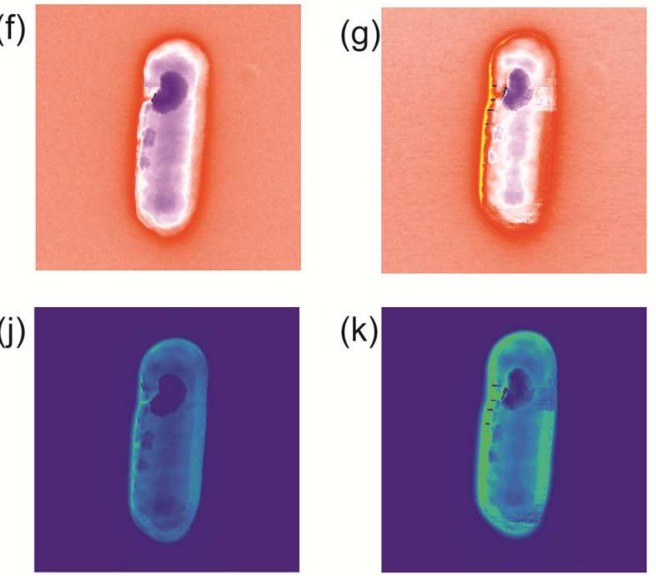

(k)

(n)

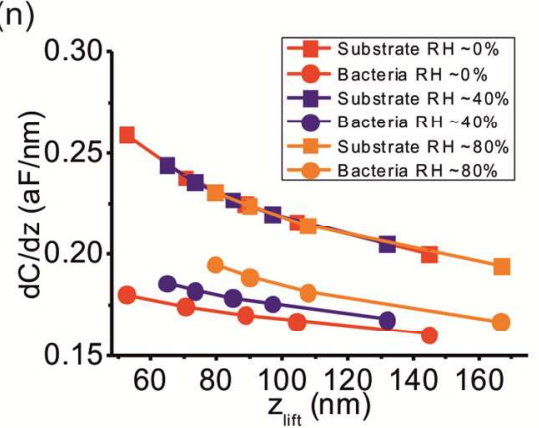

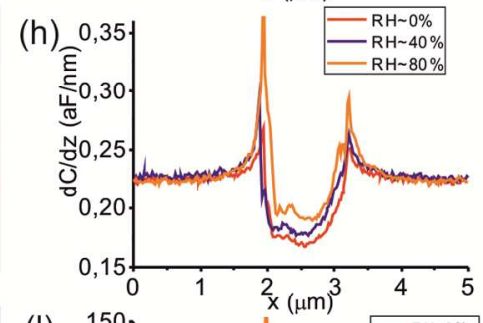

(I)

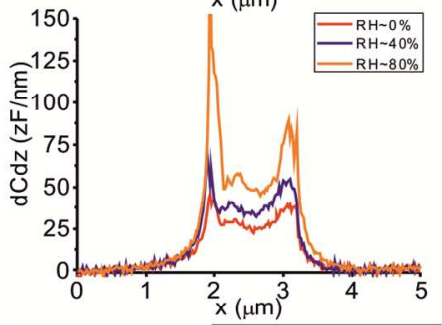

(o)

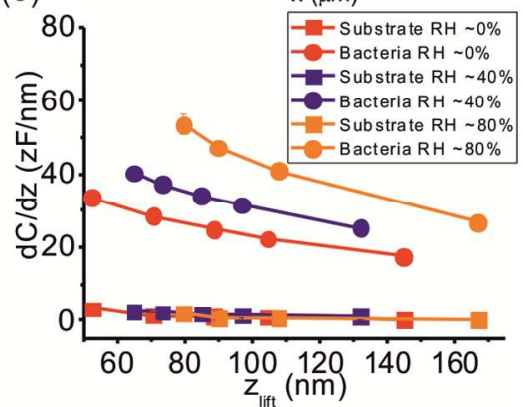

Figure 2. (a) Topographic, (e) lift capacitance gradient and (i) intrinsic capacitance gradient images of a $B$. cereus vegetative cell obtained under dry conditions (RH $\sim \%$ ) at a lift distance $z_{\text {liff }}=89 \mathrm{~nm} .(\mathrm{b}),(\mathrm{f})$ and (j) idem at RH 40\% and lift distance $z_{\text {lift }}=85 \mathrm{~nm}$. (c), (g) and (k) idem at $\mathrm{RH} \sim 80 \%$ and lift distance $z_{\text {lift }}=90 \mathrm{~nm}$. (d), (h) and (l) show the corresponding cross-section profiles along the lines drawn in the images. (m) Capacitance gradient approach curve on the bare substrate (black line). Symbols represent the values extracted from the images and used to determine the lift distances (red $\mathrm{RH} \sim 0 \%$, blue $\mathrm{RH} \sim 40 \%$ and orange $\mathrm{RH} \sim 80 \%$ ). The red line (almost indistinguishable) is a theoretical fit to the experimental data used to calibrate the tip geometry, giving in this case $R=63 \pm 2 \mathrm{~nm}, \theta=27 \pm 1^{\circ}$, and $k_{\text {stray }}=0.040 \pm 0.002 \mathrm{aF} / \mathrm{nm}$. (n) Lift 
capacitance gradient values as a function of the lift distance obtained from the lift images on the bare substrate (squares) and on the center of the vegetative cell (circles). (o) Idem from the intrinsic capacitance gradient images. The error in the data represented by the symbols is of the order of $0.002 \mathrm{aF} / \mathrm{nm}$, being smaller than the symbol size.

The intrinsic capacitance gradient images in Figures $2 \mathrm{i}, 2 \mathrm{j}$ and $2 \mathrm{k}$, together with the crosssection profiles in Figure 21 and the values on the center of the vegetative $B$. cereus cell as a function of lift distance in Figure 2o, show again that the variation in the dielectric response for varying environmental $\mathrm{RH}$ levels cannot be attributed to a change in the dimensions of the bacterial cell, but to a change in its electric permittivity properties. Therefore, we conclude that, as observed for the endospores, $B$. cereus vegetative bacterial cells also adsorb moisture from the environment, showing a direct correlation between the $\mathrm{RH}$ level and the dielectric response.

We addressed next the question whether the overall hydration properties, as well as the internal water distribution, of endospores and vegetative cells is the same or whether they offer distinct properties. To this end, we address the problematics of determining the equivalent homogeneous electric permittivity values of both bacterial entities, as well as their surface and internal electric permittivities.

To address this problem we consider the core-shell model shown schematically in Figure 3a. This model mimics in a simplified manner the internal structures of the endospore, as it can be inferred from the TEM image shown in Figure 3b. In the model the core represents the core of the endospore, while the shell represents the outer shells of the endospore, which include the inner membrane, the cortex and the coat. For the vegetative cell we also use the same type of geometric model. However, in this case the core represents the cytoplasmatic region and the shell 
the cell wall, which includes the inner membrane and the thick peptidoglycan layer characteristic of Gram-positive bacterial cells (see Supporting Information). We assume in the model (i)

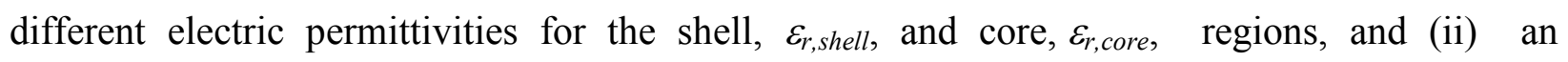
ellipsoidal shape for the endospore (3D simulations required). The model takes into account the actual sample and tip dimension, which are obtained, respectively, from a tip deconvolution analysis of the topographic images (see Supporting Information) and from a tip calibration procedure based on a capacitance gradient approach curve measured on the bare substrate (see Figures $1 \mathrm{~m}$ and $2 \mathrm{~m}$ for the corresponding calibration curves for endospore and bacterial cell measurements, respectively, and the Materials and Methods section). An example of the electric potential distribution of the modeled system is shown in Figure 3c. 
(a)

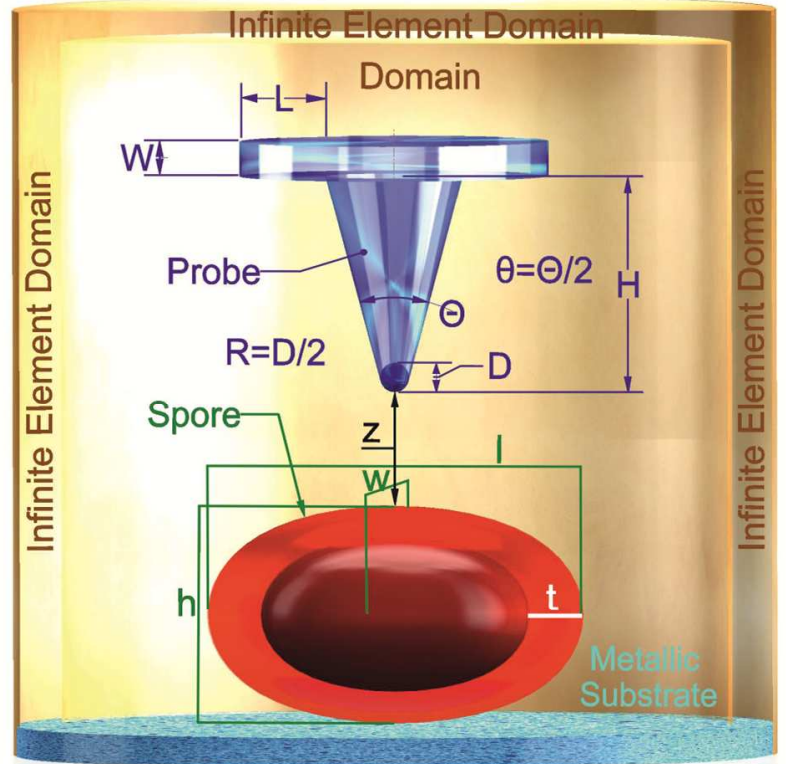

(b)

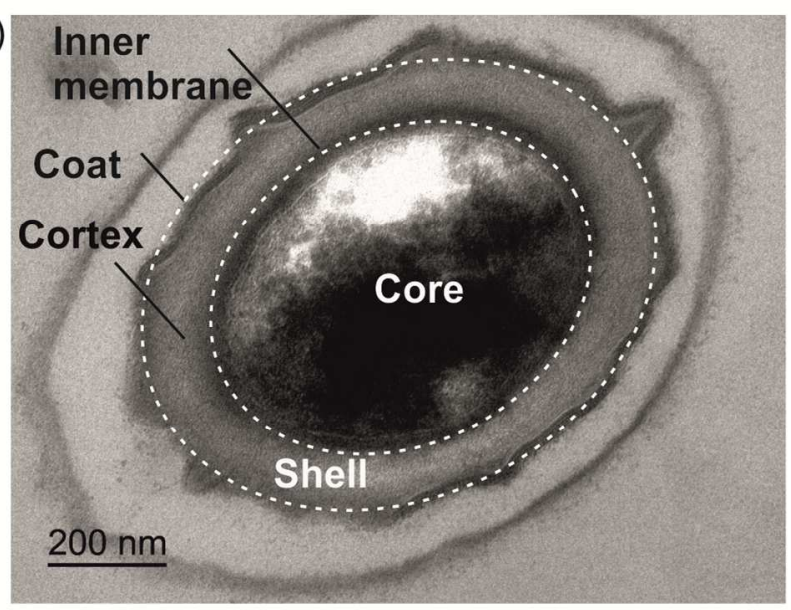

(c)

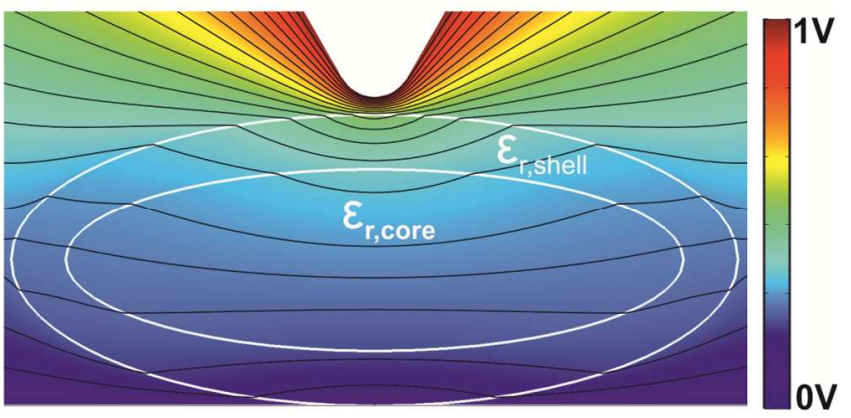

Figure 3. (a) Schematic representation of the tip-endospore model used in the finite element numerical calculations, with the model parameters indicated. (b) Transmission Electron Microscopy image of a cross-section cut of an endospore, with its main parts indicated. The dashed lines represent the division of the endospore in the core-shell model. (c) Example of the 
electric potential distribution for a tip-endospore system configuration. Parameters of the simulation: $h=800 \mathrm{~nm}, l=2000 \mathrm{~nm}, w=1000 \mathrm{~nm}, \varepsilon_{r, \text { core }}=8$ and $\varepsilon_{r, \text { shell }}=4, R=100 \mathrm{~nm}, \theta=30^{\circ}, H=12.5$ $\mu \mathrm{m}, W=3 \mu \mathrm{m}, L=0 \mu \mathrm{m}$ and $z=50 \mathrm{~nm}$.

To determine the equivalent homogeneous electric permittivity of the endospore and of the bacterial cell, $\varepsilon_{r, e f f}$, we consider a fitting procedure by setting in the model $\varepsilon_{r, \text { core }}=\varepsilon_{r, \text { shell }}=\varepsilon_{r, \text { eff }}$. Figure $4 \mathrm{a}$ (res. 4b) shows the results (lines) of the calculated capacitance gradient values on the center of the endospore (res. vegetative cell), as a function of the lift distance, for the values of the equivalent homogeneous electric permittivity that best fit the experimental data (circles). The continuous lines represent the best fit curves, while the dashed lines represent curves at plus and minus one standard deviation of the fit. Red, blue and orange colors represent measurements at RH $0 \%, 40 \%$ and $80 \%$, respectively. We also show on the plots the capacitance gradient values calculated for the tip on the bare metallic substrate (black line) and the experimental values measured there (squares). From the fitting of the theoretical predictions to the experimental data, we obtain for the endospore equivalent homogeneous relative electric permittivities: $\varepsilon_{r, e f f, s p o r e}=4.3 \pm 0.3,5.8 \pm 0.5$ and $17 \pm 4$, for $\mathrm{RH}=0 \%, 40 \%$ and $80 \%$, respectively. For the vegetative cell, instead, we obtain: $\varepsilon_{r, \text { eff, bact }}=5.0 \pm 0.5,9.5 \pm 1$ and $70 \pm 30$, respectively (see Figure $4 \mathrm{c}$ ).

The fitted equivalent homogeneous electric permittivities reveal that the global electric permittivity properties of the endospore and of the vegetative cell follow a relatively similar trend, namely, they show a relative small variation from $\mathrm{RH} 0 \%$ to $40 \%$ followed by a large variation from $\mathrm{RH} 40 \%$ to $80 \%$. We observe, in addition, that the vegetative cell shows a higher relative variation of its permittivity as compared to the endospore. These results indicate that both the endospore and the vegetative cell hydrates significantly starting at around $40 \% \mathrm{RH}$ levels, and that the latter shows a more hygroscopic behaviour than the former. This latter 
observation supports previous statements made in the literature on this aspect based on population studies, ${ }^{20,22}$ here demonstrated at the single endospore and vegetative cell levels.
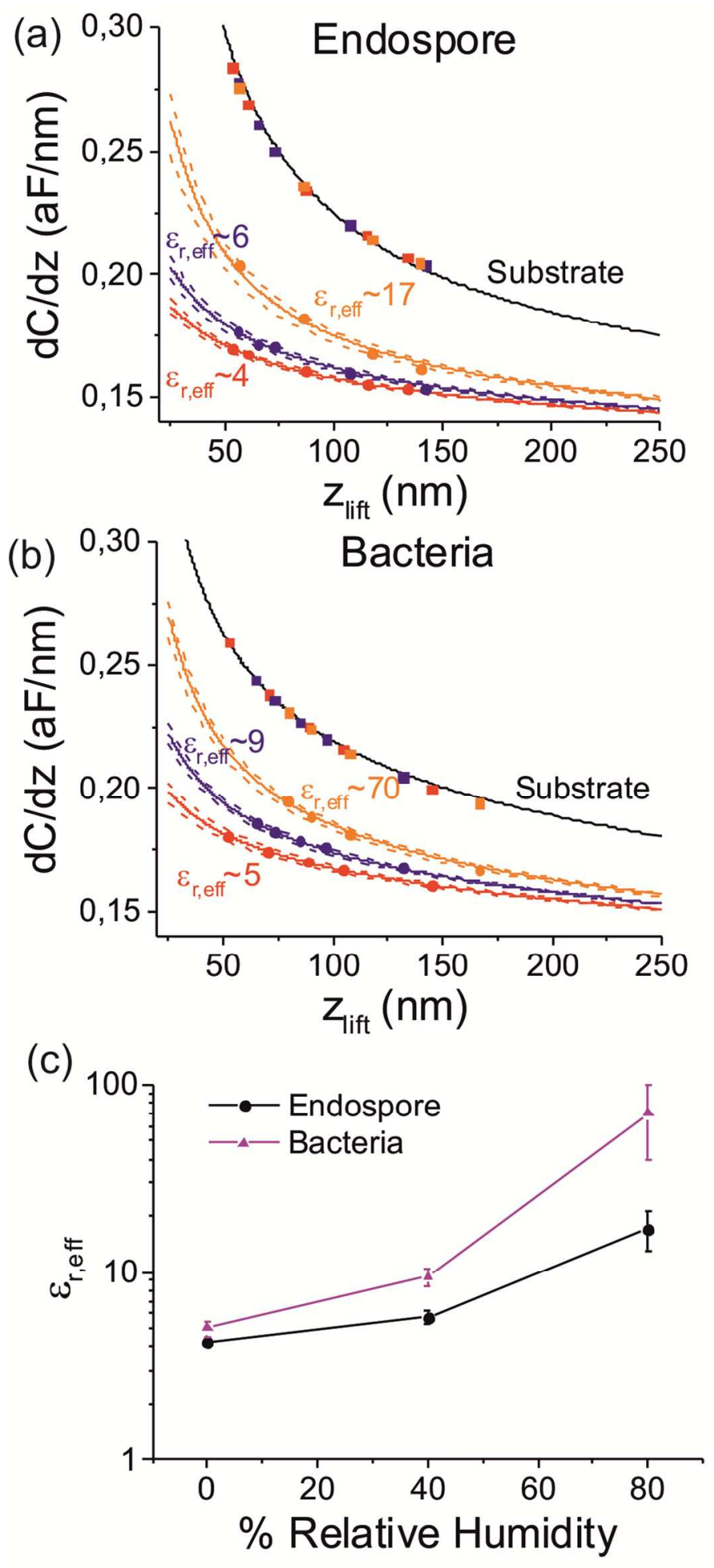

ACS Paragon Plus Environment 
Figure 4. (a) (lines) Theoretical capacitance gradient as a function of lift distance for a tip located on the center of the endospore for different values of the equivalent homogeneous relative electric permittivity of the endospore (red $0 \% \mathrm{RH}$, blue $40 \% \mathrm{RH}$ and orange $80 \% \mathrm{RH}$ lines). The black line shows the corresponding curve on the metal substrate. The continuous lines represent the theoretical curve that best fits the experimental data, while the dashed lines represent plus minus a standard deviation. The symbols represent the experimental values obtained from the lift capacitance gradient images (same as in Figure 1n). The extracted equivalent homogeneous permittivities are $\varepsilon_{r, \text { eff,endospore }}=4.3 \pm 0.3,5.8 \pm 0.5$ and $17 \pm 4$, for $\mathrm{RH}=0 \%$, $40 \%$ and $80 \%$, respectively. Tip parameters: $R=133 \mathrm{~nm}, \theta=20^{\circ}$ and $k_{\text {stray }}=0.066 \mathrm{aF} / \mathrm{nm}$, obtained from the calibration curve in Figure 1m. Endospore dimensions: $l=2020 \mathrm{~nm}$ and $w=980 \mathrm{~nm}$ (obtained from a tip deconvolution analysis) and $h=825 \mathrm{~nm}, 842 \mathrm{~nm}$ and $858 \mathrm{~nm}$ for $\mathrm{RH}=0 \%$, $40 \%$ and $80 \%$, respectively (obtained from topographic profiles). (b) Idem for the vegetative cell measurements giving $\varepsilon_{r, \text { eff,bact }}=5.0 \pm 0.5,9.5 \pm 1$ and $70 \pm 30$, for $\mathrm{RH}=0 \%, \quad 40 \%$ and $80 \%$, respectively. Tip parameters: $R=63 \mathrm{~nm}, \theta=27^{\circ}$ and $k_{\text {stray }}=0.040 \mathrm{aF} / \mathrm{nm}$ (obtained from the calibration curve in Figure $2 \mathrm{~m}$ ). Vegetative cell dimensions: $l=3450 \mathrm{~nm}$ and $w=960 \mathrm{~nm}$ (obtained from a tip deconvolution analysis) and $h=622 \mathrm{~nm}, 643 \mathrm{~nm}$ and $670 \mathrm{~nm}$ for $\mathrm{RH}=0 \%, 40 \%$ and $80 \%$, respectively (obtained from topographic profiles). (c) Plot of the extracted equivalent homogeneous relative electric permittivity as a function of the \% Relative Humidity, for a bacterial endospore (black symbols) and a vegetative cell (pink). The line is a guide to the eyes.

Based on these results, we now analyze how the electric permittivity values of the internal parts of the endospore (and vegetative cell) evolve with the environmental humidity. To this end we consider the theoretical model with different electric permittivities for the core, $\varepsilon_{r, c o r e}$, and the 
shell, $\varepsilon_{r, \text { shell, }}$ and determine those values compatible with the measured equivalent homogeneous electric permittivity, $\varepsilon_{r, \text { eff,exp }}$, i.e. those values solving the relation $\varepsilon_{r, \text { eff }}\left(\varepsilon_{r, \text { shell, }}, \varepsilon_{r, \text { core }}\right)=\varepsilon_{r, \text { eff,exp }}($ see the Materials and Method section and refs 45, 46 for further details). In the calculations, the thickness values of the shell are $t \sim 160 \pm 20 \mathrm{~nm}$ for the endospore, and $t \sim 60 \pm 10 \mathrm{~nm}$ for the vegetative cell, as obtained from the TEM images in Figure $3 b$ and in the Supporting Information. Moreover, we use lateral dimensions characteristic of the values obtained from the AFM images: $h_{s p}=800 \mathrm{~nm}, l_{s p}=2 \mu \mathrm{m}$ and $w_{s p}=950 \mathrm{~nm}$ for the endospore, and $h_{b a c}=600 \mathrm{~nm}$, $l_{b a c}=3.5 \mu \mathrm{m}$ and $w_{b a c}=950 \mathrm{~nm}$ for the bacterial cell. For the tip geometry we use $R=100 \mathrm{~nm}$ and $\theta=30^{\circ}$, and a lift distance $z_{l i f t}=50 \mathrm{~nm}$, in both cases, since the results are almost insensitive to these parameters. $^{46}$

Figures 5a (res. 5b) shows plots of the couples of values $\left(\varepsilon_{r, \text { core }}, \varepsilon_{r, \text { shell }}\right)$ which are compatible with the measured equivalent homogeneous electric permittivity, $\varepsilon_{r, \text { eff,exp }}$, for the endospore (res. bacterial cell), for the different environmental humidity conditions considered (red $\mathrm{RH} \sim 0 \%$, blue $40 \%$, and orange $80 \%$ ). From the curves represented in Figures $5 \mathrm{a}$ and $5 \mathrm{~b}$ we can investigate the evolution of the electric permittivities of the core and shell regions as a function of RH. We start by assuming that the electric permittivity of the shell of the endospore and of the vegetative cell at $0 \% \mathrm{RH}$ is $\varepsilon_{r, s h e l l, R H 0^{-3}}-4$, a range of values compatible with that of dry proteins and lipids, which are their main components. ${ }^{45,48,49}$ By assuming these range of values the plot predicts a core permittivity for the endospore at $0 \% \mathrm{RH}$ of $\varepsilon_{r, \text { core, RHO }} 4-8$, and of $\varepsilon_{r, \text { core,RHO }} 6-7$ for the vegetative cell. Both values are slightly larger than that of proteins and lipids, what can be explained the presence of also DNA in the core and cytoplasmic regions (note that DNA has a larger electric permittivity $\left.\varepsilon_{r, D N A} \sim 8\right){ }^{49}$ 

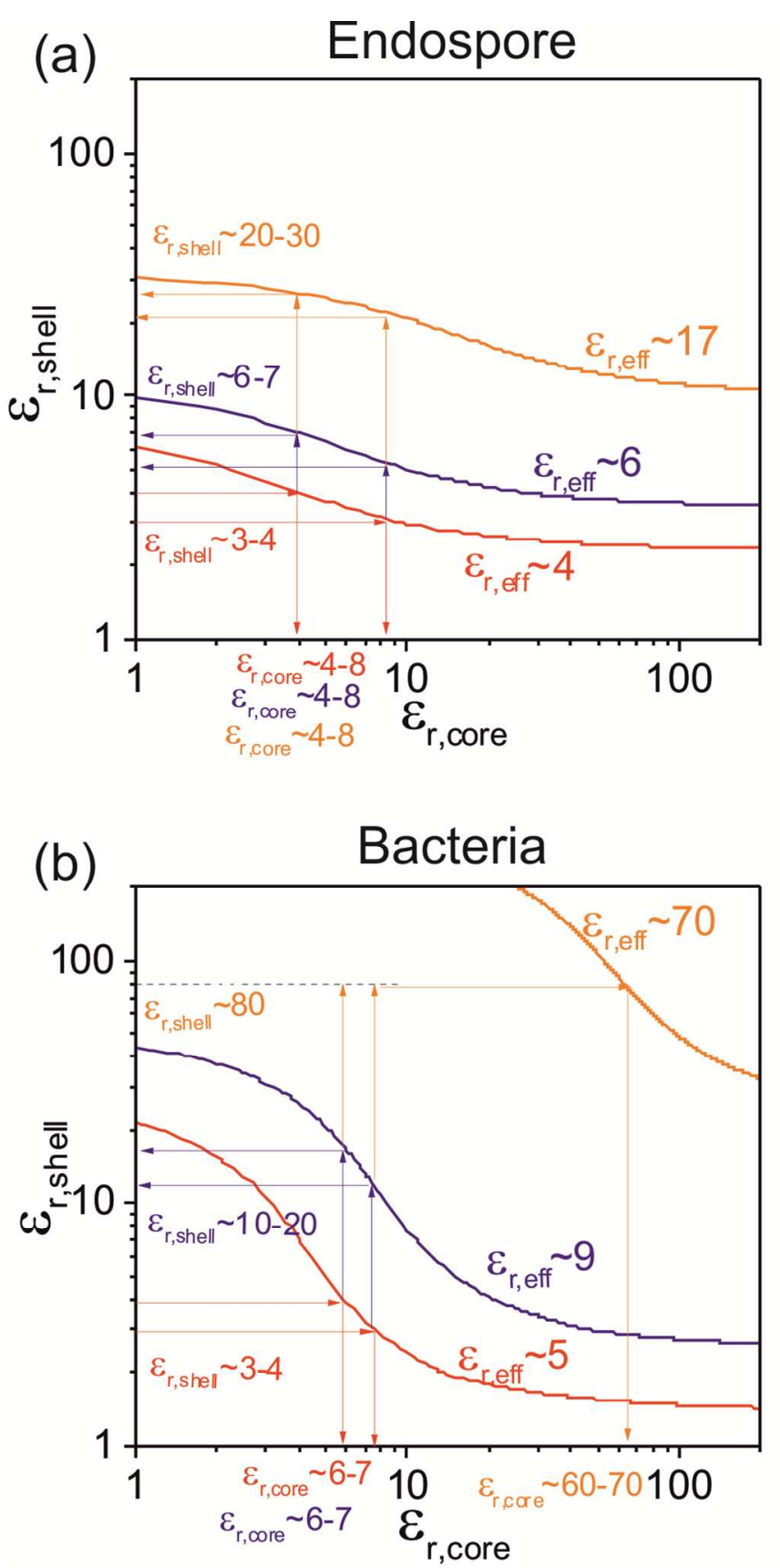

Figure 5. (a) and (b) Curves of values $\left(\varepsilon_{r, \text { core }}, \varepsilon_{r, \text { shell }}\right)$ compatible with the measured equivalent homogeneous electric permittivity of the endospore and the vegetative cell, respectively, under different environmental humidity conditions (red $\mathrm{RH} \sim 0 \%$, blue $40 \%$ and orange $80 \%$ ). Geometrical parameters used in the calculations: $h_{s p}=800 \mathrm{~nm}, l_{s p}=2 \mu \mathrm{m}$ and $w_{s p}=950 \mathrm{~nm}$ for the endospore; and $h_{b a c}=600 \mathrm{~nm}, l_{b a c}=3.5 \mu \mathrm{m}$ and $w_{b a c}=950 \mathrm{~nm}$ for the bacterial cell. For the tip 
geometry we used $R=100 \mathrm{~nm}$ and $\theta=30^{\circ}$, and a lift distance $z_{\text {liff }}=50$. The thin arrow lines help in determining the core and shell values in each case.

When the $\mathrm{RH}$ is increased to $40 \%$ the results shown in Figures $5 \mathrm{a}$ and $5 \mathrm{~b}$ are both compatible with keeping the core at the same hydration level than at $0 \% \mathrm{RH}$ and increasing the shell permittivity to $\varepsilon_{r, \text { shell,RH40 }} 6-7$ for the endospore and to $\varepsilon_{r, s h e l l, R H 40} \sim 10-20$ for the bacterial cell. This would mean that the outer shells of both the endospore and the vegetative cell are able to accommodate the moisture adsorbed at low RH levels. In the case of the endospore, it produces only a slight hydration of the shell, while on the vegetative cell it is already relatively large at these RH levels. When considering a RH value of $80 \%$ we obtain that the shell of the endospore is still able to accommodate the moisture and leave the core non-hydrated. In this case, the hydration level of the shell is already relatively large, giving an electric permittivity of $\varepsilon_{r, \text { shell,RH8O }}=20-30$. Instead, for the vegetative cell, at $\mathrm{RH} \sim 80 \%$ the moisture can no longer be accommodated by the shell region, as it would imply an unphysically large value of its permittivity, $\varepsilon_{r, \text { shell,RH40,bac }}>\varepsilon_{\text {r,water }} \sim 80$. A solution in this case is that part of the moisture penetrates to the core region (the cytoplasmic region). If we assume for instance the limiting case of $\varepsilon_{r, \text { shell,RH80,bac }} \sim 80$ then one would have $\varepsilon_{\mathrm{r}, \mathrm{core}, \mathrm{RH} 80, \mathrm{bac}} \sim 60-70$, also indicating a large hydration level of the cytoplasmic region.

The previous results support the statement that endospores have an innate mechanism to avoid hydration of the core even at large environmental relative humidity levels. This mechanism enables the core remaining almost dry, and hence, enables the endospore to extend dormancy under atmospheric conditions. ${ }^{3,5-7,9,10}$

The mechanism by which the core is kept at low levels of hydration is still the subject of debate. The current view assumes that the main role is played by the inner membrane, which, in 
dormant endospores, is largely immobile and greatly reduces water permeation, ${ }^{9,26}$ thus preserving the core from being hydrated. On the other hand, the subsequent layer, the cortex, is believed to be hydratable $\mathrm{e}^{54}$ and can accommodate a large proportion of the water content of the endospore when the endospore is fully hydrated (note that the external layer, the coat, is permeable to water ${ }^{14}$ and, when the endospore is hydrated, tends to show lower water content than the cortex). ${ }^{9,23}$

The present approach based on quantitative environmental EFM provides some fundamental advantages to study the internal hydration properties of single bacterial endospores with respect to other existing micro/nanotechniques used to date. ${ }^{19-23}$ First, it is non-destructive and thus it allows varying in situ the environmental humidity conditions on a given endospore. Second, being the electric forces long ranged, it allows accessing the internal dielectric properties of the endospore, and hence, proposing models of internal hydration by making use of the known internal structure of the endospores. And finally, it provides also in situ access to eventual variations of the physical dimensions of the endospore with nanoscale spatial resolution, thus avoiding ambiguous interpretation of the results.

To end up, we note that the present methodology can be applied to other numerous problems where the internal hydration properties of small scale objects is of major interest. Examples could include the study of the hydration properties of other biological entities, such as fungi endospores or single virus particles, and of humidity dependent biological process, such as the production of mycotoxins, one of the largest food poisoning threats. ${ }^{55}$ Similarly, it could be applied to the study of the nanoscale hygroscopic properties of water responsive materials for energy harvesting ${ }^{56,57}$ or of aerosol nanoparticles of interest in atmospheric sciences. ${ }^{58}$ 
We have demonstrated that quantitative Electrostatic Force Microscopy under relative humidity control can be applied to the important problem of determining the internal hydration properties of single bacterial endospores. In particular, we have demonstrated that individual endospores of Bacillus cereus show a small variation of its equivalent homogeneous electric permittivity from $0 \%$ to $40 \%$, followed by a large variation from $40 \%$ to $80 \%$. These results suggested that bacterial endospores hardly hydrate at low RH but, that they become significantly hydrated at larger RH. The analysis of these results by means of a core-shell model, which includes the internal structure of the bacterial endospores, has demonstrated that the external layers of the bacterial endospores (inner membrane, cortex and coat) can accommodate most of the moisture adsorbed by the endospore, even at the high relative humidity levels analyzed here (up to $80 \% \mathrm{RH}$ ), thus leaving the core of the endospore at low hydration levels. On the contrary, on bacterial cells, the cell wall is not able to accommodate all the moisture at high hydration levels and the cytoplasmic region becomes highly hydrated. This differential behavior is key to enable endospores to remain viable in its dormant state under atmospheric conditions, and could be at the basis of the large water mechanical responsive properties of bacterial endospores. Present results show the potential of quantitative EFM to analyze the hygroscopic and internal hydration properties of small scale objects, with important implications in both Life and Material sciences.

MATERIALS AND METHODS

Endospore and vegetative cell growth and sample preparation. Bacillus cereus (CECT495)

was used in this study. Cells were grown as previously described. ${ }^{31}$ Endospores were obtained by 
growing cells in $\mathrm{G}$ medium for $48 \mathrm{~h}$. This culture time guaranteed that complete mature bacterial endospores are formed. Non sporulating vegetative bacterial cells were cultured in Trypticase soy broth (Scharlau) for $24 \mathrm{~h}$ at $30^{\circ} \mathrm{C}$ and $250 \mathrm{rpm}$. For AFM and EFM imaging, the samples were deposited on a gold substrate (Arrandee), previously cleaned following sequential sonication washing with acetone, isopropanol and water. Samples were allowed to dry in a cabin flow before imaging.

Atomic and Electrostatic Force Microscopy imaging. Topographic and capacitance gradient images have been obtained with a commercial AFM system (Nanotec Electronica, S.L.) following the electrostatic force microscopy two pass mode detailed elsewhere. ${ }^{47}$ Briefly, during the first pass the topographic line is obtained in conventional intermittent contact mode, followed by a second pass, in which the tip moves at a constant height from the measured sample topography, $z_{l i f t}$ (lift-mode), while an electric potential of amplitude $3 \mathrm{~V} \mathrm{rms}$ and $2 \mathrm{kHz}$ frequency is applied. In the second pass, the electrically induced oscillation amplitude at double of the excitation frequency $\left(A_{2 \omega}\right)$ is measured by an external lock-in amplifier (Anfatec Instruments AG). Conversion of the oscillation amplitude (rms value in volts) into the capacitance gradient is done by means of the relationship

$$
\frac{d C}{d z}=\frac{2 \sqrt{2}}{v_{r m s}^{2}} k \frac{\left(A_{2 \omega}-A_{2 \omega, o f f s e t}\right)}{m G}
$$

where $k$ is the equivalent spring constant of the cantilever, $v_{r m s}$ the rms voltage amplitude, $A_{2 \omega, \text { offset }}$, the lock-in offset, $m$ the optical lever sensitivity and $G$ the lock-in gain. Typical values of these parameters are $m \sim 3 \mathrm{mV} / \mathrm{nm}, A_{2 \omega, \text { offset }} \sim 15 \mathrm{mV}, G \sim 500, v_{r m s} \sim 3 \mathrm{~V}, k \sim 0.5 \mathrm{~N} / \mathrm{m}$ and $A_{2 \omega} \sim 0-4$ V. The absolute capacitance gradients values are then in the range $\sim 0-0.4 \mathrm{aF} / \mathrm{nm}$, with a 
sensitivity down to $\sim 0.002 \mathrm{aF} / \mathrm{nm}$. Capacitance gradient approach curves have also been measured on given points of the sample. These curves are used to determine the lift distances at which the EFM images are acquired by comparing the absolute value of the capacitance gradient in a bare part of the substrate of the EFM image with the values of the approach curve measured on this part of the sample. To help in the interpretation of the results, intrinsic capacitance gradient images (in which topographic crosstalk contributions are removed) have also been constructed following the methodology recently developed by us. ${ }^{47}$ A custom-made software written in Matlab (Mathworks Inc.) was developed to automatize these processes.

CDT-CONTR doped diamond probes (Nanosensors) of spring constant $\sim 0.5 \mathrm{~N} / \mathrm{m}$ and nominal tip radius $\sim 100 \mathrm{~nm}$ have been used all through this study. Imaging has been performed under nitrogen ambient flow ( $\sim 0 \%$ Relative Humidity), and under RH $\sim 40 \%$ and $\sim 80 \%$ with the help of a homemade environmental EFM system. In this system, the ambient RH humidity of the AFM glass enclosure is regulated by a pump and monitored with a humidity sensor (Rotronic AG). Times $>15$ min where allowed after each change of humidity for system stabilization.

To monitor eventual changes on the photodiode sensitivity, or on tip geometry, after each set of EFM measurements at a given RH condition, a set of $\mathrm{N}=5 \mathrm{EFM}$ approach curves were measured and analyzed following the specific methodology detailed in the Supporting Information.

\section{D finite element numerical calculations and internal electric permittivity quantification.}

The internal electric permittivity properties of the endospores and vegetative cells have been determined with the help of $3 \mathrm{D}$ finite element numerical calculations. To this end we used the model system schematically shown in Figure 3a. The endospore and the vegetative cell are assumed to have an ellipsoid shape (3D simulations required), and its internal structure is 
represented, in a simplified way, by a core and a shell, which are assumed to have different electric permittitvities, $\varepsilon_{r, \text { core }}$ and $\varepsilon_{r \text {,shell, }}$, respectively. The width, $w$, height, $h$, and length $l$, of the endospore are obtained from the topographic AFM images after a tip deconvolution analysis similar to that of ref 59 , but including also the cone contact region. In the present case, the cone contact region is relevant due to the large height of the bacterial endospores in relation to the tip radii of the probes (see Supporting Information). The thickness, $t$, of the shell is determined from the TEM images, as detailed below. The tip radius, $R$, and cone half angle, $\theta$, are obtained from a least square fitting of the theoretical model to a capacitance gradient approach curve recorded on the substrate, as explained elsewhere ${ }^{45}$ (other parameters are set to nominal values: cone height $H=12.5 \mu \mathrm{m}$, cantilever thickness $W=3 \mu \mathrm{m}$ and cantilever "length" $L=0 \mu \mathrm{m})$. The microscopic cantilever effects are included in a constant stray offset, $k_{\text {stray }}$. We have not included in the model the eventual presence of a thin water layer on the metallic substrate since, for the present work, its contribution can be shown to be negligible. Indeed, we estimated a maximum contribution to the capacitance gradient signal of around $\sim 0.5 \mathrm{zF} / \mathrm{nm}$ for a water layer of a few nanometers for the tip geometries used in the present work. ${ }^{60}$ This value is smaller than the noise of the measuring set-up $\sim 2 \mathrm{zF} / \mathrm{nm}$ and much smaller than the measured capacitance gradient contrasts $>20 \mathrm{zF} / \mathrm{nm}$, so that its effect can be safely neglected.

The capacitance gradient between the tip and sample is calculated by solving Poisson's equation with the finite element software Comsol Multiphysics 5.2 (AC/DC electrostatic module). Poisson's equation solution results in the distribution of the static electric potential around the tip and in the sample (an example is shown in Figure 3c), from which we derive the Maxwell stress tensor on the tip surface, and, by integration of it on the surface of the tip, we obtain the electrostatic force. ${ }^{47}$ Software routines written in Matlab (Mathworks Inc.) have been 
used to move the tip in the simulations with respect to the sample and to calculate the capacitance gradient at different lift distances, $z_{\text {lift }}$.

To determine the internal electric permittivities of the core and shell, we proceeded in a two step process. In the first step we determined the equivalent homogeneous electric permittivity, $\varepsilon_{r, e f f}$, of the endospore (and bacterial cell), by following a fitting procedure similar to the one detailed elsewhere, ${ }^{45-47}$ but applied, here, to the case of lift EFM images. In a nutshell, we fitted the experimental capacitance gradient values on the center of the endospore (and vegetative cell) obtained from the lift EFM images with the corresponding values obtained from the 3D numerical calculations, by setting $\varepsilon_{r, \text { core }}=\varepsilon_{r, \text { shell }}=\varepsilon_{r, \text { eff }}$, with $\varepsilon_{r, \text { eff }}$ being the single fitting parameter. In a second step, by means of $3 \mathrm{D}$ finite element numerical calculations, we determine the relationship between the equivalent homogeneous electric permittivity and the core and shell permittivities, $\varepsilon_{r, \text { eff }}=\varepsilon_{r, \text { eff }}\left(\varepsilon_{r, \text { shell, }} \varepsilon_{r, \text { core }}\right)$, and from this relationship, we determine the couples of

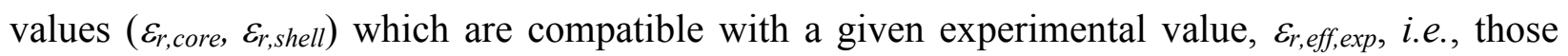
values solving the relationship $\varepsilon_{r, \text { eff }}\left(\varepsilon_{r, \text { shell }}, \varepsilon_{r, \text { core }}\right)=\varepsilon_{r, \text { eff,exp. }}{ }^{45,46}$

Transmission Electron Microscopy imaging. Mature bacterial endospores and vegetative cells were directly fixed with $2.5 \%$ glutaraldehyde and post fixated with $2 \%$ osmium tetroxide. Samples were allowed to dehydrate in a graded acetone series. Samples were embedded into an epoxy resin and allow polymerization before performing thin sections (thickness $\sim 90 \mathrm{~nm}$ ) with an ultramicrotome (Leica Ultracut E). Observations of the sections were performed with a JEOL 1010 transmission electron microscope with a tungsten filament operating at $80 \mathrm{kV}$. Digital images were captured with a GATAN ORIUS CCD camera.

\section{ASSOCIATED CONTENT}


Supporting Information: Monitoring photodiode sensitivity and tip geometry, topography tip de-convolution, experimental data for different lift distances, TEM image of vegetative cell. This material is available free of charge via the Internet at http://pubs.acs.org

\section{AUTHOR INFORMATION \\ Corresponding Author \\ *ggomila@ibecbarcelona.eu}

\section{Author Contributions}

The manuscript was written through contributions of all authors. All authors have given approval to the final version of the manuscript.

\section{Funding Sources}

European Commission, Nanomicrowave project (FP7/People-2012-ITN, grant agreement n³17116.EU). Spanish Government, projects TEC2013-48344-C2 and and BIO2013-49148-C21R. Generalitat de Catalunya, ICREA Academia grant.

\section{ACKNOWLEDGMENTS}

This work has been partially supported by the Nanomicrowave project funded from the European Union Seventh Framework Programme (FP7/People-2012-ITN) under grant agreement $\mathrm{n}^{\circ}$ 317116.EU, and also by the Spanish projects TEC2013-48344-C2 and BIO2013-49148-C21R. (GG) acknowledges support from an ICREA Academia grant from the Generalitat de Catalunya. We acknowledge M C Biagi from IBEC for technical support and J M Rebled from the CCiT-UB for Transmission Electron Microscopy images.

\section{REFERENCES}

(1) Bacterial Spores: Current Research and Applications; Abel-Santos, E., Ed.; Caister 
Academic Press: Norfolk UK, 2012.

(2) Setlow, P. Spores of Bacillus Subtilis: Their Resistance to and Killing by Radiation, Heat and Chemicals. J. Appl. Microbiol. 2006, 101, 514-525.

(3) Nicholson, W. L.; Munakata, N.; Horneck, G.; Melosh, H. J.; Setlow, P. Resistance of Bacillus Endospores to Extreme Terrestrial and Extraterrestrial Environments. Microbiol. Mol. Biol. Rev. 2000, 64, 548-572.

(4) Rothschild, L. J.; Mancinelli, R. L. Life in Extreme Environments. Nature 2001, 409, 1092-1101.

(5) Cowan, A. E.; Koppel, D. E.; Setlow, B.; Setlow, P. A Soluble Protein Is Immobile in Dormant Spores of Bacillus Subtilis but Is Mobile in Germinated Spores: Implications for Spore Dormancy. Proc. Natl. Acad. Sci. U. S. A. 2003, 100, 4209-4214.

(6) Beaman, T. C.; Gerhardt, P. Heat Resistance of Bacterial Spores Correlated with Protoplast Dehydration, Mineralization, and Thermal Adaptation. Appl. Environ. Microbiol. 1986, 52, 1242-1246.

(7) Setlow, P. Mechanisms Which Contribute to the Long-Term Survival of Spores of Bacillus Species. J. Appl. Bacteriol. 1994, 76, 49S-60S.

(8) Driks, A.; Setlow, P.; Setlow, P. Morphogenesis and Properties of the Bacterial Spore. In Prokaryotic Development; Brun, Y. V.; Shimkets, L. J., Eds.; American Society of Microbiology, 2000; pp. 191-218.

(9) Sunde, E. P.; Setlow, P.; Hederstedt, L.; Halle, B. The Physical State of Water in Bacterial 
Spores. Proc. Natl. Acad. Sci. U. S. A. 2009, 106, 19334-19339.

(10) Rupley, J. A.; Careri, G. Protein Hydration and Function. Adv. Protein Chem. 1991, 41, $37-172$.

(11) Hughes, T.; Strongin, B.; Gao, F. P.; Vijayvergiya, V.; Busath, D. D.; Davis, R. C. AFM Visualization of Mobile Influenza A M2 Molecules in Planar Bilayers. Biophys. J. 2004, $87,311-322$.

(12) Kaieda, S.; Setlow, B.; Setlow, P.; Halle, B. Mobility of Core Water in Bacillus Subtilis Spores by 2H NMR. Biophys. J. 2013, 105, 2016-2023.

(13) Ablett, S.; Darke, A. H.; Lillford, P. J.; Martin, D. R. Glass Formation and Dormancy in Bacterial Spores. Int. J. Food Sci. Technol. 1999, 34, 59-69.

(14) Westphal, A. J.; Price, P. B.; Leighton, T. J.; Wheeler, K. E. Kinetics of Size Changes of Individual Bacillus Thuringiensis Spores in Response to Changes in Relative Humidity. Proc. Natl. Acad. Sci. U. S. A. 2003, 100, 3461-3466.

(15) Driks, A. The Dynamic Spore. Proc. Natl. Acad. Sci. U. S. A. 2003, 100, 3007-3009.

(16) Chen, X.; Mahadevan, L.; Driks, A.; Sahin, O. Bacillus Spores as Building Blocks for Stimuli-Responsive Materials and Nanogenerators. Nat. Nanotechnol. 2014, 9, 137-141.

(17) Chen, X.; Goodnight, D.; Gao, Z.; Cavusoglu, A. H.; Sabharwal, N.; DeLay, M.; Driks, A.; Sahin, O. Scaling up Nanoscale Water-Driven Energy Conversion into EvaporationDriven Engines and Generators. Nat. Commun. 2015, 6, 7346.

(18) Sreeprasad, T. S.; Nguyen, P.; Alshogeathri, A.; Hibbeler, L.; Martinez, F.; McNeil, N.; 
Berry, V. Graphene Quantum Dots Interfaced with Single Bacterial Spore for BioElectromechanical Devices: A Graphene Cytobot. Sci. Rep. 2015, 5, 9138.

(19) Leuschner, R. G. K.; Lillford, P. J. Effects of Hydration on Molecular Mobility in PhaseBright Bacillus Subtilis Spores. Microbiology 2000, 146, 49-55.

(20) Waldham, D. G.; Halvorson, H. O. Studies on the Relationship between Equilibrium Vapor Pressure and Moisture Content of Bacterial Endospores. Appl. Microbiol. 1954, 2, $333-338$.

(21) Carstensen, E. L.; Marquis, R. E.; Gerhardt, P. Dielectric Study of the Physical State of Electrolytes and Water Within Bacillus Cereus. J. Bacteriol. 1971, 107, 106.

(22) Henry, B. S.; Friedman, C. A. The Water Content of Bacterial Spores. J. Bacteriol. 1937, $33,323-329$.

(23) Algie, J. E.; Watt, I. C. Calculation of Mass and Water Content between the Core, Cortex, and Coat of Bacillus Stearothermophilus Spores. Curr. Microbiol. 1984, 10, 249-253.

(24) Ghosal, S.; Leighton, T. J.; Wheeler, K. E.; Hutcheon, I. D.; Weber, P. K. Spatially Resolved Characterization of Water and Ion Incorporation in Bacillus Spores. Appl. Environ. Microbiol. 2010, 76, 3275-3282.

(25) Kong, L.; Setlow, P.; Li, Y. Direct Analysis of Water Content and Movement in Single Dormant Bacterial Spores Using Confocal Raman Microspectroscopy and Raman Imaging. Anal. Chem. 2013, 85, 7094-7101.

(26) Cowan, A. E.; Olivastro, E. M.; Koppel, D. E.; Loshon, C. a; Setlow, B.; Setlow, P. Lipids 
in the Inner Membrane of Dormant Spores of Bacillus Species Are Largely Immobile. Proc. Natl. Acad. Sci. U. S. A. 2004, 101, 7733-7738.

(27) Rubel, G. O. A Non-Intrusive Method for the Measurement of Water Vapour Sorption by Bacterial Spores. J. Appl. Microbiol. 1997, 83, 243-247.

(28) Knudsen, S. M.; Cermak, N.; Feijó Delgado, F.; Setlow, B.; Setlow, P.; Manalis, S. R. Water and Small-Molecule Permeation of Dormant Bacillus Subtilis Spores. J. Bacteriol. 2016, 198, 168-177.

(29) Plomp, M.; Leighton, T. J.; Wheeler, K. E.; Malkin, A. J. The High-Resolution Architecture and Structural Dynamics of Bacillus Spores. Biophys. J. 2005, 88, 603-608.

(30) Plomp, M.; Leighton, T. J.; Wheeler, K. E.; Hill, H. D.; Malkin, A. J. In Vitro HighResolution Structural Dynamics of Single Germinating Bacterial Spores. Proc. Natl. Acad. Sci. U. S. A. 2007, 104, 9644-9649.

(31) Wang, C.; Stanciu, C.; Ehrhardt, C. J.; Yadavalli, V. K. Morphological and Mechanical Imaging of Bacillus Cereus Spore Formation at the Nanoscale. J. Microsc. 2015, 0, 1-10.

(32) Rusciano, G.; Zito, G.; Isticato, R.; Sirec, T.; Ricca, E.; Bailo, E.; Sasso, A. Nanoscale Chemical Imaging of Bacillus Subtilis Spores by Combining Tip-Enhanced Raman Scattering and Advanced Statistical Tools. ACS Nano 2014, 8, 12300-12309.

(33) Martin, Y.; Abraham, D. W.; Wickramasinghe, H. K. High-Resolution Capacitance Measurement and Potentiometry by Force Microscopy. Appl. Phys. Lett. 1988, 52, 11031105. 
(34) Girard, P. Electrostatic Force Microscopy: Principles and Some Applications to Semiconductors. Nanotechnology 2001, 12, 485-490.

(35) Fumagalli, L.; Gramse, G.; Esteban-Ferrer, D.; Edwards, M. a.; Gomila, G. Quantifying the Dielectric Constant of Thick Insulators Using Electrostatic Force Microscopy. Appl. Phys. Lett. 2010, 96, 183107.

(36) Krayev, A. V.; Talroze, R. V. Electric Force Microscopy of Dielectric Heterogeneous Polymer Blends. Polymer 2004, 45, 8195-8200.

(37) Crider, P. S.; Majewski, M. R.; Zhang, J.; Oukris, H.; Israeloff, N. E. Local Dielectric Spectroscopy of Polymer Films. Appl. Phys. Lett. 2007, 91, 13102.

(38) Riedel, C.; Arinero, R.; Tordjeman, P.; Lévêque, G.; Schwartz, G. a.; Alegria, A.; Colmenero, J. Nanodielectric Mapping of a Model Polystyrene-Poly(vinyl Acetate) Blend by Electrostatic Force Microscopy. Phys. Rev. E 2010, 81, 10801.

(39) Yang, Y.; Guo, W.; Wang, X.; Wang, Z.; Qi, J.; Zhang, Y. Size Dependence of Dielectric Constant in a Single Pencil-like ZnO Nanowire. Nano Lett. 2012, 12, 1919-1922.

(40) Lu, W.; Wang, D.; Chen, L. Near-Static Dielectric Polarization of Individual Carbon Nanotubes. Nano Lett. 2007, 7, 2729-2733.

(41) Lu, W.; Xiong, Y.; Hassanien, A.; Zhao, W.; Zheng, M.; Chen, L. A Scanning Probe Microscopy Based Assay for Single-Walled Carbon Nanotube Metallicity. Nano Lett. 2009, 9, 1668-1672.

(42) Krauss, T. D.; Brus, L. E. Charge, Polarizability, and Photoionization of Single 
Semiconductor Nanocrystals. Phys. Rev. Lett. 1999, 83, 4840-4843.

(43) Cherniavskaya, O.; Chen, L.; Weng, V.; Yuditsky, L.; Brus, L. E. Quantitative Noncontact Electrostatic Force Imaging of Nanocrystal Polarizability. J. Phys. Chem. B 2003, 107, 1525-1531.

(44) Ben-Porat, C. H.; Cherniavskaya, O.; Brus, L.; Cho, K.-S.; Murray, C. B. Electric Fields on Oxidized Silicon Surfaces: Static Polarization of PbSe Nanocrystals. J. Phys. Chem. A 2004, 108, 7814-7819.

(45) Fumagalli, L.; Esteban-Ferrer, D.; Cuervo, A.; Carrascosa, J. L.; Gomila, G. Label-Free Identification of Single Dielectric Nanoparticles and Viruses with Ultraweak Polarization Forces. Nat. Mater. 2012, 11, 808-816.

(46) Esteban-Ferrer, D.; Edwards, M. A.; Fumagalli, L.; Juárez, A.; Gomila, G. Electric Polarization Properties of Single Bacteria Measured with Electrostatic Force Microscopy. ACS Nano 2014, 8, 9843-9849.

(47) Van Der Hofstadt, M.; Fabregas, R.; Biagi, M. C.; Fumagalli, L.; Gomila, G. Nanoscale Dielectric Microscopy of Non-Planar Samples by Lift-Mode Electrostatic Force Microscopy. Nanotechnology 2016, 27, 405706.

(48) Dols-Perez, A.; Gramse, G.; Calò, A.; Gomila, G.; Fumagalli, L. Nanoscale Electric Polarizability of Ultrathin Biolayers on Insulating Substrates by Electrostatic Force Microscopy. Nanoscale 2015, 7, 18327-18336.

(49) Cuervo, A.; Dans, P. D.; Carrascosa, J. L.; Orozco, M.; Gomila, G.; Fumagalli, L. Direct 
Measurement of the Dielectric Polarization Properties of DNA. Proc. Natl. Acad. Sci. U. S. A. 2014, 111, E3624-30.

(50) Bockrath, M.; Markovic, N.; Shepard, A.; Tinkham, M.; Gurevich, L.; Kouwenhoven, L. P.; Wu, M. W.; Sohn, L. L. Scanned Conductance Microscopy of Carbon Nanotubes and $\lambda$-DNA. Nano Lett. 2002, 2, 187-190.

(51) Jespersen, T. S.; Nygard, J. Mapping of Individual Carbon Nanotubes in Polymer/nanotube Composites Using Electrostatic Force Microscopy. Appl. Phys. Lett. 2007, 90, 8-11.

(52) Cadena, M. J.; Misiego, R.; Smith, K. C.; Avila, A.; Pipes, B.; Reifenberger, R.; Raman, A. Sub-Surface Imaging of Carbon Nanotube-Polymer Composites Using Dynamic AFM Methods. Nanotechnology 2013, 24, 135706.

(53) Zhao, M.; Gu, X.; Lowther, S. E.; Park, C.; Jean, Y. C.; Nguyen, T. Subsurface Characterization of Carbon Nanotubes in Polymer Composites via Quantitative Electric Force Microscopy. Nanotechnology 2010, 21, 225702.

(54) Gould, G. W.; Dring, G. J. Heat Resistance of Bacterial Endospores and Concept of an Expanded Osmoregulatory Cortex. Nature 1975, 258, 402-405.

(55) Peraica, M.; Radić, B.; Lucić, A.; Pavlović, M. Toxic Effects of Mycotoxins in Humans. Bull. W. H. O. 1999, 77, 754-766.

(56) Ma, M.; Guo, L.; Anderson, D. G.; Langer, R. Bio-Inspired Polymer Composite Actuator and Generator Driven by Water Gradients. Science 2013, 339, 186-189. 
(57) Kim, H.; Kwon, S. Water-Responsive Polymer Composites on the Move. Science 2013, $339,150-151$.

(58) Cheng, Y.; Su, H.; Koop, T.; Mikhailov, E.; Pöschl, U. Size Dependence of Phase Transitions in Aerosol Nanoparticles. Nat. Commun. 2015, 6, 5923.

(59) Biagi, M. C.; Fabregas, R.; Gramse, G.; Van Der Hofstadt, M.; Juárez, A.; Kienberger, F.; Fumagalli, L.; Gomila, G. Nanoscale Electric Permittivity of Single Bacterial Cells at Gigahertz Frequencies by Scanning Microwave Microscopy. ACS Nano 2016, 10, 280288.

(60) Gomila, G.; Gramse, G.; Fumagalli, L. Finite-Size Effects and Analytical Modeling of Electrostatic Force Microscopy Applied to Dielectric Films. Nanotechnology 2014, 25, 255702 .

TOC

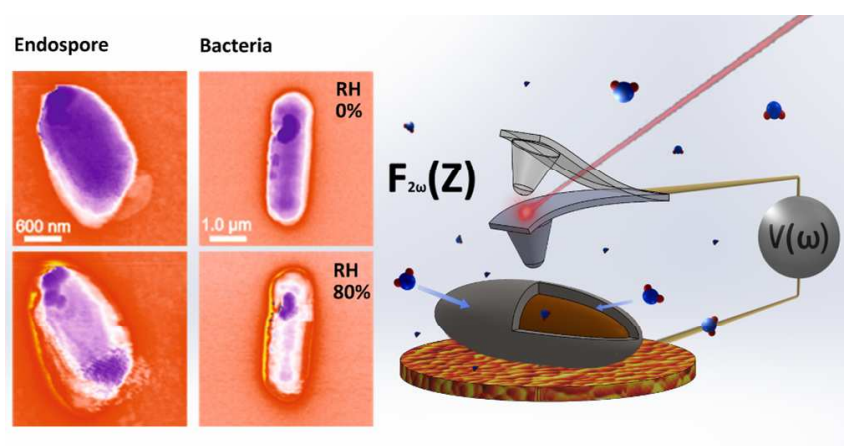

ACS Paragon Plus Environment 